\title{
ÉTICA NO TRABALHO CIENTÍFICO
}

\author{
Newton Sergio De CARVALHO*
}

De Carvalho NS. Ética no trabalho científico.

DESCRITORES - Ética profissional. Artigo de revista. Redação.

Deve-se considerar a Ética como sendo um termo genérico englobando diversas reflexões sobre as relações entre os seres humanos e seu modo de ser e de pensar. Encontra-se disseminada em todas as atividades onde possa existir o confronto entre o bem e o mal, ou melhor, ações positivas ou negativas. Ainda, como sendo uma reflexão filosófica sobre de como devemos viver, portanto sobre questões de certo e errado, bom e mau, direito e deveres. Dentro das publicações científicas se enquadra na Bioética, ou seja, a ética aplicada às áreas das Ciências da Vida e da Saúde. Assim, tem-se a Bioética como regente da Ética na Pesquisa Clínica e esta obedece aos seguintes princípios básicos resumidos abaixo:

1. Autonomia: que requer do profissional respeito à vontade, à crença, aos valores morais do paciente (também chamado sujeito de pesquisa), reconhecendo o domínio sobre sua própria vida e o respeito a sua intimidade. Este princípio gera várias discussões, sobretudo quando o poder decisório do paciente possa estar comprometido, como no caso dos chamados grupos vulneráveis (p. ex. menores de idade, indígenas, débeis mentais, pacientes terminais, militares, etc). Relacionando este principio com a Pesquisa, encontramos o "termo de consentimento livre e esclarecido" a ser aplicado pelo pesquisador e assentido pelos sujeitos da pesquisa ou seus representantes legais como sendo o ponto principal.

2. Beneficência: que deve assegurar o bem-estar das pessoas, evitando danos e garantindo que sejam atendidos seus interesses. Trata-se de princípio indissociável ao da autonomia.

3. Não maleficência: onde se assegura que sejam minorados ou evitados danos físicos aos sujeitos da pesquisa ou pacientes. Riscos da pesquisa são as possibilidades de danos de dimensão física, psíquica, moral, intelectual, social, cultural ou espiritual do ser humano, em qualquer uma de suas fases ou dela decorrente.

4. Justiça: onde se exige equidade na distribuição de bens e benefícios em qualquer setor da ciência.

5. Proporcionalidade: priorizando o equilíbrio entre os riscos e benefícios, visando alcançar o menor mal e o maior benefício às pessoas. Está intimamente relacionado com os riscos da pesquisa clínica, os danos e o princípio da justiça.

Em relação ao Trabalho Científico fundamentado na Pesquisa Clínica, pode-se dizer que o processo se inicia na "inquietude intelectual" do pesquisador ou de um grupo de pesquisadores que, a partir de uma dúvida ou de uma ideia, decide realizar um trabalho científico para responder a suas perguntas ou viabilizar a sua ideia. Tal processo, fundamentalmente, deve seguir normas científicas rígidas e éticas. Esta obediência deve se manter desde esta fase inicial até a publicação ou estágio final de toda a pesquisa. Obviamente que a não publicação implica na não divulgação e, portanto, não se torna disponível para a comunidade científica ou população leiga, podendo ser considerada até mesmo como não tendo sido realizada. Alguns fundamentos de interesse a este respeito são referentes a sua realização e publicação.

\section{REALIZAÇÃO DO TRABALHO CIENTÍFICO}

Eticamente deve obedecer às leis internacionais denominadas de Boas Práticas Clínicas consideradas como padrões de qualidade científica e ética internacional para o desenho, condução, registro e relato de estudos que envolvam a participação de seres humanos. Baseiam-se na Declaração de Helsinki e a adesão a este padrão assegura a garantia pública de que os direitos, a segurança e o bem-estar dos pacientes participantes destes estudos estejam protegidos, bem como a credibilidade dos dados. Nacionalmente estão fundamentadas na resolução 196 de 1996 do Conselho Nacional de Saúde (para leis nacionais veja = conselho. saude.gov.br/comissao/.../resolucao.html e, www.anvisa. gov.br/medicamentos/.../boaspraticas_americas e para realizar um curso de GCP on line veja, www.onlinegcp. org, e www.fda.gov/.../RunningClinicalTrials, ).

Estas normas surgiram a partir dos abusos cometidos em pesquisas com humanos, realizadas de acordo com o único interesse do Estado, no esforço de guerra tanto da Alemanha como nos países aliados, bem como no interesse científico - como nos três casos paradigmáticos * Setor de Pesquisa Clinica e Infecções em Ginecologia e Obstetrícia do Departamento de Tocoginecologia da Universidade Federal do Paraná, Curitiba, PR.
Correspondência: Dr. Newton Sergio de Carvalho - Rua Saldanha Marinho, 1422 - apt. 801 - Curitiba PR. E-mail: newton@hc.ufpr.br 
de abusos em pesquisas nos Estados Unidos no pós-guerra (Tuskegee Syphilis Study de 1932 a 1972, Jewish Chronic Disease Hospital em 1963 e no Willowbrook State Schoolem 1956) -. Dentre estes, o mais comentado é o episódio de Tuskegee, onde de 1940 a 1972, no Alabama, EUA, cerca de 400 negros, a maioria analfabeta, com sífilis foram seguidos sem qualquer tratamento, visando a estabelecer a história natural da sífilis, apesar do surgimento em larga escala da penicilina como tratamento eficaz, em 1945. Esse fato só foi descoberto em 1973 e posteriormente mereceu inclusive o pedido de desculpas por parte do governo americano.

Pode-se dizer que o princípio moral relevante que é o da autonomia dos sujeitos de pesquisa, considerado o princípiomor da experimentação humana, emerge no pós-guerra com o Código de Nuremberg (1947), destacando o consentimento voluntário do ser humano como sendo absolutamente essencial. Neste, afirma-se que o sujeito, objeto da pesquisa, deve poder "exercer o livre direito de escolha sem qualquer intervenção de elementos de força, fraude, mentira, coação, astúcia ou outra forma de restrição posterior".

Portanto, na execução de qualquer pesquisa envolvendo seres humanos, entre vários pontos importantes, ressalte-se: - Comitê de Etica em Pesquisa em Seres Humanos é o órgão institucional que tem por objetivo proteger o bem-estar dos indivíduos pesquisados. É um comitê independente, interdisciplinar, constituído por profissionais de ambos os sexos, além de pelo menos um representante da comunidade, que tem por função avaliar os projetos de pesquisa que envolva a participação de seres humanos. Nos Estados Unidos estes comitês são denominados de IRB (Institutional Review Board). No Brasil estão interligados a um Comitê Central denominado Comitê Nacional de Ética em Pesquisa - CONEP.

- Termo de Consentimento Livre e Esclarecido (TCLE). Trata-se de um documento onde, em linguagem clara e em nível de entendimento do sujeito da pesquisa, o pesquisador deverá explicar e esclarecer cada passo do que está sendo proposto. Após completamente entendido e concordado, deverá ser assinado e datado por ambos, ficando uma cópia com o paciente e outra nos arquivos do estudo. Entendido este consentimento como livre por não poder haver nenhum tipo de limitação a influenciar a vontade e a decisão do sujeito da pesquisa, e esclarecido na medida em que se considera que o compromisso com o sujeito da pesquisa não é apenas de informar, mas, sobretudo, de esclarecer. Sua redação não merece ser feita visando à proteção do pesquisador, da instituição ou do patrocinador. Devem, ainda, estar claramente especificados os possíveis desconfortos, os riscos e os possíveis benefícios; como o paciente poderá obter continuidade caso venha a se beneficiar do tratamento e como será indenizado ou tratado por problemas decorrentes da pesquisa. $\mathrm{O}$ sujeito deverá estar seguro da privacidade de todas as informações. $\mathrm{O}$ pesquisador deverá deixar claro como procederá à informação em casos de incapacidade mental (crianças ou adultos com retardo mental), clínica (pacientes inconscientes) ou culturais (por exemplo, indígenas).
Igualmente deverá constar um contato explícito (telefone do pesquisador p. ex) na existência de qualquer dúvida ou problema durante a pesquisa por parte do participante. Também deverá estar informado que o participante poderá retirar seu consentimento em qualquer ocasião, sem nenhum prejuízo no seu atendimento posterior dentro da Instituição.

\section{PUBLICAÇÃO DO TRABALHO CIENTÍFICO}

Após coleta e análise dos dados, o estudo deverá ser enviado para publicação e neste particular alguns pontos são fundamentais:

- De início, quem elabora um comunicado científico está convencido da relevância e exatidão dos seus achados, que devem ser referendados pela Comissão Editorial da revista a que é submetido, compartilhando da confiabilidade e relevância dos dados. Ou seja, existe um compromisso ético com o leitor e com a comunidade científica.

- Desta forma, durante o processo de investigação, bem como na publicação, é completa falta de ética apresentar dados de outros como se fossem seus; falsificar total ou parcialmente ou ainda, suprimir ou alterar dados que não estejam de acordo com o objetivo proposto.

Com alguma frequência publicam-se notícias em jornais leigos referindo a fraude em pesquisa, como esta onde a revista Science se retratou de um artigo publicado em 2006 que continha fotos manipuladas por um ex-pesquisador. A publicação se corrigiu logo depois que a Universidade de Missouri-Columbia anunciou que uma investigação descobriu que o estudante de pós-doutorado Kaushik Deb adulterou imagens de embriões de ratos (publicado no "O Estado de São Paulo" em 31/7/2007), ou mesmo em matéria científica como nesta metanálise, citando que em até $34 \%$ dos cientistas estrangeiros admitem ter realizado práticas de pesquisa questionáveis, como omitir novos resultados que colocariam em xeque trabalhos anteriores ou descartar certas informações obtidas em experimentos por uma percepção meramente subjetiva de que estariam incorretas. Foi o que mostrou uma revisão sistemática de artigos sobre má conduta científica realizada por Daniele Fanelli, do Instituto para o Estudo da Ciência, Tecnologia e Inovação da Universidade de Edimburgo, na Escócia (Fanelli D. How many scientists fabricate and falsify research? A systematic review and metaanalysis of survey data.. PLoS One. 2009 May 29;4(5):e5738)

- Dentro deste raciocínio, igualmente é inobservância à Ética enviar o mesmo relato científico para mais de um periódico ou mesmo apresentá-lo em mais de um evento científico a não ser que o autor possa justificar tal atitude, e em comum acordo com os respectivos coordenadores ou editores científicos. As citações da literatura devem espelhar exatamente os textos originais para evitarem falhas e impedimento de localizar o trabalho citado. $\mathrm{O}$ autor deve ter permissão em mãos para citarem dados ainda não publicados, obtidos pessoalmente de outro pesquisador, bem como devem ser citados fontes de diagramas, quadros, figuras e imagens 
obtidos em outros locais e com permissão. A publicação de imagens de pacientes deverá ter a autorização e a identidade dos mesmos preservada.

- Em relação à listagem dos autores do trabalho deve-se considerar que, para que alguém possa ser colocado no grupo, deveria, à luz da ética, apresentar contribuição substancial à concepção e ao desenho do trabalho, aquisição, interpretação e análise dos dados ou ter participado na redação e revisão crítica, com real contribuição intelectual ao seu conteúdo, e ainda, ter aprovado o final do conteúdo a ser publicado. Alguns periódicos solicitam que os autores justifiquem suas respectivas atuações nos trabalhos e essas observações devem ser obedecidas.

A ordem dos autores na citação deve ser feita de comum acordo entre todos os autores, sendo o primeiro o mais relevante e o último o coordenador do projeto (sênior). Os autores intermediários podem ser citados em ordem de contribuição para o trabalho final. Todos os autores devem participar na redação e editoração do manuscrito, receber cópia do mesmo e concordar em compartilhar a responsabilidade pelos resultados e igualmente fornecer esta anuência na ocasião de envio para publicação. Portanto, adicionar autores por conveniência e sem participação efetiva nas etapas do trabalho constitui infração à Ética. Um dos abusos cometidos observado em algumas situações é a inclusão, como último autor, do chefe do grupo, tenha participado ou não do trabalho e com finalidade de agradar ao superior hierárquico ou mesmo tentar usar o seu nome e prestígio para valorizar o estudo.
Por fim, ponto de fundamental necessidade a ser apontado frente à Ética nas Publicações são os chamados Conflitos de Interesses e, em relação a este ponto, o Conselho Federal de Medicina emite normativa (Resolução CFM n. 1.595/2000). Nesta, além de definir uma série de conflitos envolvendo a profissão Médica, no seu artigo $2^{\circ}$ determina que os médicos, ao proferir palestras ou escrever artigos divulgando ou promovendo produtos farmacêuticos ou equipamentos para uso na Medicina, devem declarar os agentes financeiros que patrocinaram suas pesquisas e/ou apresentações, cabendo-lhes ainda indicar a metodologia empregada, quando for o caso - ou referir a literatura e bibliografia que serviram de base à apresentação, quando essa tiver por natureza a transmissão de conhecimento proveniente de fontes alheias. Refere-se ainda que os editores médicos de periódicos e os responsáveis pelos eventos científicos em que artigos, mensagens e matérias promocionais forem apresentados, são corresponsáveis pelo cumprimento das formalidades prescritas nesse artigo. Desta forma, após o título do artigo ou no início da apresentação científica onde se informa a qualificação, dever-se-á igualmente apontar os eventuais pontos de Conflito de Interesses que possam influir no juízo do leitor em relação ao conteúdo do trabalho publicado.

Concluindo, cabe aos pesquisadores a postura consciente de que cada vez mais, a qualidade deverá suplantar a quantidade, e certamente, mais do que legislações e/ou regulamentações vigentes, a nossa consciência Ética tem o papel decisivo na definição "do que" e "como" se publica, bem como do impacto que se obterá na transmissão do conhecimento.

De Carvalho NS. The ethics of writing a scientific paper. Arq Gastroenterol. 2009;46(3):164-6.

HEADINGS - Journal article. Writing. Ethics, professional.

\section{LEITURAS SELECIONADAS}

1. Beecher HK. Ethics and clinical research. New Engl J Med. 1966;274:1354-60

2. Puri KS, Suresh KR, Gogtay NJ, Thatte UM. Declaration of Helsinki, 2008 implications for stakeholders in research. J Postgrad Med. 2009;55:131-4.
3. Schramm FR, Palácios M, Rego S. O modelo bioético principialista para a análise da modalidade da pesquisa científica envolvendo seres humanos ainda é satisfatória? Ciênc Saúde Coletiva. 2008;13:361-70.

4. Uniform requirements for manuscripts submitted to biomedical journals. International Committee of Medical Journals Editors. Ann Intern Med 1997;126:36-47. 